\title{
'Around the Meeting Tree': methodological reflections on using digital tools for research into Indigenous adult education in the Networking Tranby project
}

REVISION for publication - version 3 - FINAL

By Heather Goodall, Heidi Norman and Belinda Russon

Based on a paper presented to ITIC conference, Melbourne, 2017.

\section{September 2018}

From the time that Tranby opened its doors in 1957 as a learning place for adult Indigenous people, it's great strength has been person-to-person interactions. Most learning took place as students came to know and trust each other, as teachers learned from students as much as students learned from teachers, and as both learned from the visitors and activists who came into Tranby to talk and plan.

There have been some historical analyses of Tranby's goals as the Australian Board of Missions' 'Co-operative for Aborigines' under its first director, the Reverend Alf Clint. Direct Indigenous control began in 1980, when Kevin Cook, Wandandian/Yuin man and unionist, from the NSW South Coast became Secretary General of the Coop, then in 1982, Bob Bellear, a Bandjalang man with Vanuatuan heritage, became Chair of the Board of Tranby Cooperative. ${ }^{1}$ Yet there had been little research into student experiences, origins or later careers. ${ }^{2}$ Each of the project's leaders has had long interaction with former students of Tranby Heather Goodall taught there in the early 1980s, Heidi Norman has taught many former Tranby students at the University of Technology Sydney and Belinda Russon, a research lawyer, taught Legal studies at Tranby and has been its CEO since 2013. So the project has aimed to seek out former students from the first two decades of Aboriginal control - 1980 to 2000 - to record their memories and learn about their experiences through ongoing person-to-person communication from their time as Tranby students (between the 1980s and the turn of the century) up to the present.

But the project title - 'Networking Tranby' - put everyone in mind of digital networks and particularly the Internet. We hoped to use social media to contact students and to help Tranby to build its reach to alumni. We were all active users of Facebook and other software, and knew that former Tranby students were also in touch with each other and a wide range of friends using these digital networks. ${ }^{3}$ So we expected that, like many Oral History projects, we would not only build communication with students through social media but also publish the audio interviews and contextual information in an online format, either on a web-site or blog or through social media.

Yet it became obvious that a social media strategy for contacting former students and for republishing research reports was more problematic than we had first understood. Among the valuable findings from this project is that the use of social media requires rethinking. 
Now - in 2018 - the scandals over social media user information being sold have exploded globally, making it clear that caution is important in any use of apparently open access cyber-networks. This paper will work through the concerns which arose as they appeared for us, from the start of the project in 2015 until, by 2018, we have moved to a more cautious use - although not a less active use - of digital technologies and strategies in our research.

There were three key components in the Networking Tranby study, each of which utilized digital research methodology or digital communication. For each of these three components, we found both strengths and weaknesses in digital approaches. The three elements were (1) the Interview - to learn from students what their experiences had been, (2) the Database - to organize the information about places of origin and years of enrolment, and (3) the Internet - to disseminate research outcomes. Before discussing these three components, we will point to the debates which both informed and problematized our work.

Our study drew on the literature from post-colonial studies and oral history. One body of post-colonial literature concerns the politics and ethics in any research situations where the power relations of colonialism continue to shape contemporary relationships and identities. Linda Tuhawai-Smith, Aileen Moreton-Robinson, Martin Nakata, Lorina Barker and Tracey Banivanua-Mar have each raised issues of the ethics and politics of research on and with Indigenous people in colonized as well as post-colonial Oceania. ${ }^{4}$ The ethical issues they raise are consistent with those pointed out concerning oral history by Alistair Thomson and Alexander Freund..$^{5}$ The common thread in all of these analyses, although it is pursued in different ways, is the need to recognize the power of the past. Research needs to be seen in historical perspective, as does the interview itself, which has developed in particular political and cultural conditions.

Research has frequently led to increased control over the lives of colonized indigenous peoples, as each of these analysts has pointed out. Stringent protocols therefore now exist around the formulation of any research project in Australia funded by bodies like the AIATSIS and Universities where Indigenous voices have been able to influence research policy. We found this concern about research was prominent: both Indigenous and non-Indigenous researchers found former students to be cautious about any research, regardless of who was conducting it.

In addition to the problem of colonial power, there is the fact that European colonization frequently impacted on peoples whose bodies of belief, history and law were held in oral forms, rather than in writing. Colonisers invariably dismissed such cultures as 'inferior', so there has been little attempt among Europeans to understand the complex meanings, multiple genres and diverse performative modes of oral traditions. Yet a hallmark of orality in most cultures is its collective and collaborative nature - while often enabling innovation, oral genres are always performed for audiences who may have greater or lesser roles in correcting or shaping the performance. So the individualized life story through personal narration - so favoured by contemporary 'oral historians' and so 
readily transferred to digital platforms - may be discouraged in oral cultural expression. This has raised serious question marks over how any recordings of 'oral history' might be understood or trusted among oral cultures.

Such issues around both trust and culture have been addressed by Lorina Barker, an Indigenous researcher from north-western NSW, in her 2006 paper “'Hangin' Out' and 'Yarnin'“.6 Barker reflected on her experience of collecting oral histories' among relations, pointing to the importance of cultural differences in transmission of life stories and memories in Indigenous settings. An underlying basis for such reflections has been the recognition that oral genres are important means of communication of both overall histories and community knowledge in all non-literate societies. These oral traditions shape the informal 'yarning' about the past and life histories which might occur in Indigenous societies in Australia today. There is a valuable body of literature on the many genres of oral traditions in non-western societies, by, from among many examples, Latukefu, Mercer, Denoon and Lacey, Fienberg and Finnegan and Orbell in the Pacific, Oslender in Latin America and Vansina in Africa. ${ }^{7}$ The argument has been developed further in recent work by Sue Anderson, Jaimee Hamilton and Lorina Barker, arguing that everyday as well as formal oral communication in Indigenous societies is subject to complex cultural conventions. ${ }^{8}$

The process of interviewing itself has been less often investigated historically. It is easy to see forebears of oral history interviewing in the interrogation techniques of police and colonial officials, but it has even deeper roots. Alex Freund argues that the interview in western cultures has arisen in the processes of imposing discipline and obedience through the Confession in the Catholic Church and, in parallel, the 'Confession' in criminal legal proceedings. ${ }^{9}$ In both cases, the interview has been a key tool in exercising invasive control. ${ }^{10}$ So 'story-telling' - the building and delivering of one's memories as a 'story' that has a narrative form and structure - is never a neutral process. Instead, it is a complex interaction not only between interviewer and interviewee, but between the power exercised by the wider society on individuals and the corresponding individual power to shape one's own 'story' - in a form and with a purpose with which one can live. This set of processes, complex enough already, is further complicated in colonial conditions, in which continuing power is being exerted by the dominant society to reshape and retell that individual 'story' so that it fits into the wider 'story' that conforms to and justifies colonialism. Alternatively, as South African historians have suggested, power may be exerted by victorious liberation movements to narrativise all lives as if they had been resistant to the former colonial processes, leaving some people feeling pressured to reluctantly tailor their less dramatic memories to fit the political movement's heroic narrative. ${ }^{11}$

Finally, there is the ubiquitous presence of contemporary media, in which personal reminiscences and interviews are widely depicted in both fiction and non-fiction. How has all of this, as Alistair Thomson has asked, shaped the ways that people think about memory and personal narrative, let alone how do they now choose to shape their lives into a story to be retold? ${ }^{12}$ 


\section{The Interview}

This project has been led by experienced researchers who have worked extensively with Indigenous people in oral and archival history. Ethical issues were addressed actively and research strategies re-evaluated continuously. All involved saw the project to be a way to record and recognize the experiences of the people who were often overlooked - not only as Indigenous people but because, as students in a learning institution, they may have felt they had little power relative to staff or administrations to have their views heard. All researchers were committed to ensuring that no pressure was to be exerted on any potential interviewees to take part, and that they could modify content or withdraw at any time. A copy of each interview has been returned to the interviewees, who are invited to edit the transcript and to identify which parts, if any, of the audio file are to be conserved. The edited sections are then to be housed at in the Tranby archives but accessed, in line with AIATSIS protocols, only on meeting any restrictions imposed by the interviewee.

Nevertheless, once the project was underway, we found our plans needed revising. We had hoped that social media would allow us to make contact with former students. We established a Facebook page, but ethical concerns meant that although the page was 'public' and so could be viewed by anyone, we limited posting to administrators only, inviting people interested in being interviewed to contact us by a separate email address. This was problematic - we could see that it would limit the interactivity of the Facebook page and lead to a lack of spontaneity, but concerns about potential harm that could come from indiscrete postings about personal histories were very real. Intensive researcher time commitments were needed for frequent 'feeding' with content and particularly images, which stimulated enthusiastic responses from those already in the network and encouraged further sharing. However, at the same time, the need to ensure adequate time for participants to review their interviews made for long delays. As a result, the Facebook strategy has been slower and less fully developed than we had hoped. So recruitment of participants for interviews proceeded only partly from responses to social media and far more often from word of mouth initiated by the research assistants and investigators along with current Tranby students and staff.

Another important plan needed revision. Despite being enthusiastic in talking and hearing memories about Tranby, both former students and Indigenous research assistants were reluctant to proceed with recorded interviews. Hesitation to be recorded might have many causes, like unfamiliarity with audio technology or the commonly-expressed feeling among interviewees that their story is not out of the ordinary and so 'no-one will want to hear it'.

Yet reluctance to proceed to interview was so persistent in this project that it really demanded further reflection. There are particular problems around Linkage or Partnership projects, the Australian Research Council's strategy for encouraging research that will have practical outcomes of benefit to specific public or commercial sectors, designated as 'partners'. This raises concerns that initially disinterested comments might be turned into advertising and not only 
governments and universities were mistrusted. Even with an organization like Tranby about which most participants expressed strongly positive attitudes, there was still fear participants would lose control and that their 'lives will be turned into commodities' in the 'partnership' process. ${ }^{13}$ So while funding bodies like the ARC may love 'partnerships', we found that the potential participants were less enthusiastic.

More often, participant concerns arose from their skepticism about research generally, even research being conducted by other Indigenous people. As discussed, this has arisen because research for Indigenous peoples has reflected at worst - intrusive colonial goals of intervention and - even at best - has seldom been seen to lead to benefit for the Indigenous people participating. ${ }^{14}$ Finally, those who had been students at Tranby over these years, 1980 to 2000, had attended many classes about critical analysis of the media and had become familiar with the exploitative and racist nature of most mainstream media.

There has been valuable work done on the use of social media among Aboriginal people. Bronwyn Carlson and Ryan Frazer record the role social media can play in allowing people of all ages to take part in mourning rituals despite now living far distant from family. ${ }^{15}$ Emma Rice and others have reviewed an extensive number of papers about social media use by young Aboriginal people. ${ }^{16}$ This literature shows that digital media play an important part in the lives of young Aboriginal people and in their interactions with family, community and friends, even those in far distant places. Yet while Rice concludes by suggesting that there may be a valuable role for social media in research, it is notable that each paper cited as demonstrating active use is an analysis of situations where Aboriginal people themselves initiate online interactions in order to sustain social or kin networks. This review in fact suggests that young people's usage is for very specific purposes and usually those in which the users have a strong sense of control. So this is NOT in fact an indication that independently-initiated 'research' will be embraced by Indigenous people, even when it is conducted by an Indigenous organization. It is instead an indication that questions of power and control are of critical importance in any Indigenous social networking interactions.

Overall, the cautious approach of former students meant we conducted fewer interviews than we had initially expected. Yet this was balanced by the depth of the interviews that were done. One Indigenous research assistant led a significant proportion of all of the interviews. As a Tranby student herself, this researcher brought an empathetic and encouraging conversational approach that led interviews into unexpected directions. The outcomes were rich, in-depth and fascinating interviews that opened up insights into experiences at Tranby that would simply not have been visible without this gifted Indigenous interviewer. This generated one of the strengths of the use of the interview method.

The cautions around interviewing led, ironically, to another strength in the interview element of the project by limiting the pace in which research outcomes could be communicated. Anna Scheftel and Stacey Zembrzycki have cited Milan Kundera in his accusation that the speed generated by modernity was aimed at 
destroying memory. ${ }^{17}$ They argue that taking time to listen carefully to interviewees' stories, to consider not just the units of information but the narrative forms, the silences and the affective interactions with the interviewer and others, all ensure greater understanding and more complex and valuable representations of the person and their memories. So 'slowness' is not an inefficiency of earlier methods of recording and transcribing oral histories, but rather a defining strength.

Our slowness was partly a result of our planning to ensure that interviewees could exercise control over all editing and presentation of their stories. As well, however, the unexpectedly modest pace of the interviewing ensured that the later stages of the project would unfold more slowly than predicted. We came to see this as a benefit, not a limitation.

Our initial products from these interviews were two hard-copy exhibitions for the local community around Glebe, composed of A2 posters with photographs and quotes from the interviewees. One was done for NAIDOC, in July 2016, and was shown in 6 locations around Glebe, including a polling booth for a ByElection being held that day, a Community Youth Centre and the local branch of the City Library. The other was for YABUN, in January 2017, and was shown in the 'Yarning Tent' to accompany the annual Kevin Cook Lecture in which, this year, the Hon. Linda Burney, Federal ALP Member for Barton and former educator, introduced two young Aboriginal people, Kali Bellear and Dr Talila Milroy, who had used further studies and tertiary education to achieve their goals. The small scale, as well as the limited audience and circulation, again proved valuable. It meant there was plenty of time for both interviewees and researchers to discuss transcripts and possible quotations and photographs.

Each exhibition was shaped by a project topic, which meant that there was analysis and selection by the project team as well as discussion with interviewees on what they wanted to contribute to that topic. The first topic was around 'neighbourhood', and it explored the way in which Tranby and its students, although drawn from across the country, related to the immediate locality of the College in Glebe. The second was about 'teaching on Country' and it investigated a series of Tranby excursions, with former teaching staff explaining what they had hoped to achieve with this method and former students explaining what - if anything - they had got out of it. The preparation of these exhibitions offered many opportunities for revision, which occurred right up until the final moments of installing the posters - and in some cases, afterwards! Posters are easy to take down, revise, and replace.

The problems of these exhibitions were however exactly these limitations of scale - the audiences who could see them were relatively small and so the discussion of these stories was limited in time and space. The internet seemed to offer a more effective life for these rich memories. Yet as we discuss in Section 3, the internet too showed weaknesses with our planning as well as strengths in what we hope to do.

\section{The Database}


The goal in developing a searchable digital database organised around individual students was to provide information for Tranby about the origins of its students. Former students and staff were aware that Tranby had always drawn enrolments from across Australia and sometimes from PNG and beyond. Current funding for Indigenous education is, however, largely state-based. While in the 1970s to 2000 period, funding from the Federal Departments of Education and of Employment welcomed nation-wide enrolments, as had the earlier Australian Board of Missions, NSW State government agencies have been reluctant to provide funding for education services to any students who did not live permanently in NSW.

Prior to this project commencing, there was intensive training for each research staff person in educational ethics. Tranby maintains complete confidentiality of any teaching-related material such as results or staff comments on student work. So as this was a 'Linkage' project, designed specifically to bring rigorous research to bear to benefit the 'industry' partner organisation (in this case Tranby), the research assistants, although employed through the University, were subject to the strict ethical requirements of Tranby.

However, in addition to the origins of students, Tranby was interested in understanding better the challenges faced by Indigenous students which might lead to discontinuation of courses and withdrawal from the College. As well as the ethical concerns of breaking confidentiality on student records, there was a reluctance among research staff to include information about particular student challenges such as substance abuse, domestic violence or poverty. Anxieties about whether this might reflect poorly on the individual or even on the area's Indigenous community were expressed by both Indigenous and non-Indigenous staff. So a carefully anonymised version of the database was established in which such information could be conserved but would no longer be associated with identifiable individuals.

There were two types of records available to the project. One was the digital records of students arising from funding bodies' requirements to record enrolments and attendance in specific courses over a year, semester or term. So information on any one student might be present in a number of digital records, making analysis of overall student numbers difficult. More importantly, such digital records had no information about student origins or other issues like reasons for withdrawal.

The other type of record was the hard-copy folder created by Tranby staff for each student on enrolment between 1980 and 2000. These folders included documents associated with each student's enrolment as well as - sometimes other documents like student essays or artwork, course reports or references. These files, arranged in alphabetical order, contained duplications for a number of reasons, such as variations in spelling, alternative surnames or use of nicknames as well as some cultural conventions requiring name changes, such as after a community death.

The project's non-Indigenous RA was allocated the task of entering content from both these types of documents into a Filemaker database, designed by the 
investigators and organised by individual student name. Each student had a single digital file into which was entered each enrolment they had had, and the data on place of origin and the other data which was gathered at enrolment. A check box recorded whether the student had been interviewed or not. A notes field allowed indications of whether other material was present in the hard copy folder, such as course reports, student work and destinations after graduation. Information on causes of any early withdrawal was recorded in the anonymised version of the database.

Although initially straightforward, this methodology showed weaknesses as we progressed. First, the categories of information entered on enrolment differed from year to year - partly as a result of changing government requirements [such as new rules demanding that applicants choose whether they would be identified as 'Aboriginal' and 'Torres Strait Islander' - but could not be both, nor Australian South Sea Islander] or changing Tranby policy - such as whether applicants were asked to write about their goals and/or their background. Second, there was diversity between applicants or between staff members about how completely the form should be filled out - so for some applicants there were many blank spaces while for others there was a great deal of accompanying background information.

The key issue for the project was the origin of the students - but although there were boxes on the forms for this information, it was often recorded only indirectly, perhaps by reference to earlier schooling or by surname and family references. This latter particularly necessitated consultation among research assistants - not only between non-Indigenous and Indigenous staff but among Indigenous staff from different areas. It often needed experiential local knowledge even to suggest whether an applicant was a member of a family from a particular area or whether a shared name was simple coincidence. There was as well a wide diversity between student folders about what had been included about course outcomes or later destinations. So it was not possible to develop a consistent database.

Finally, for the Indigenous participants, there was an uneasiness about the idea of a database being developed at all, even though the project was a partnership with Tranby, the database excluded confidential student results and the interviews themselves had little direct input into the database entries. It was simply that databases have a chilling potential to record and link disparate forms of information and utilise it in unanticipated ways. This was simply too reminiscent of the bitterly resented colonial interventions in the lives of so many Indigenous people - whether to refuse exemption certificates or to remove children or to withhold welfare payments.

The strength of this component of the research has been in its results - it has allowed Tranby for the first time to demonstrate the nation-wide range of its recruitment during the 1980 to 2000 period. This has been expressed graphically as a map for the Tranby website which demonstrates the historical continuity in Tranby's role as a national education and training provider. This map visually demonstrates the networks of connection and relationships that led to batches of enrolments and so have powered the outcomes of Tranby - one of 
which has always been living, interactive people-to-people relationships. The importance of the interviews is then to explore what such person-to-person relationships may have been like for the people involved. Nevertheless, we have reassessed some planned further uses for the database, particularly online access.

\section{3: Using the Internet to communicate the interviews}

The expectations of many researchers and curators working with oral history now is that interviews will be uploaded in full or part to the web. Funding bodies like the ARC and many others encourage online dissemination. Sherna BergerGluck, a leading historian in using digital resources for feminist oral history projects, has reflected recently on her own practice. She argues that as people's life circumstances change, material that they had happily consented to be published in the past will become problematic for them and they will need to withdraw their consent. Berger-Gluck now works in continuous review with each interviewee whose recordings are disseminated on the sites she has developed. ${ }^{18}$ Drawing on Berger-Gluck's experiences in the US and on their own work in Canada, Anna Sheftel and Stacey Zembrzycki argue that on-line dissemination inevitably undermines the degree of control which interviewees have over their own story and even their own voices. They argue cogently for caution in online dissemination or analysis. ${ }^{19}$ Alexander Freund similarly cautioned that rising popular fears of identify theft and misuse of oral history recordings and transcripts are well founded. ${ }^{20}$ None of these historians is suggesting that digital technologies and online dissemination should be abandoned. They are, however, calling on historians who are advocates of oral history - particularly those who have explored gendered memory - to be just as critical and analytical about digital tools as they have been in the past about the broader assumptions of oral history. Only in this way, they argue, can they sustain their commitments to collaborative and democratized research relationships in which authority really was shared. To achieve this in a digital environment may require significant effort and commitment to counter the pressure of the technology and its advocates.

The internet appears to offer the benefits of speed - in analysis (by 'clipping' or 'indexing' audio not text) and accessibility (by making audio and interpretations widely available). Yet these benefits, Sheftel and Zembrzycki argue, are illusory. Citing Kundera's bitter accusation that the speed of modernity is aimed at killing memory, they point out that speed will remove the great advantages achieved by oral history in its current form of empathetic and detailed listening to interviewees' voices. This 'slow listening' allows not only 'indexed' or 'clipped' units of information to be amassed, but the wider meanings of whole narrative structures to be recognized. Silences can be attended to and reflected on.

Revisions can be made and authority can be genuinely shared. The promised 'accessibility' of online dissemination only occurs where interviewees and other have the technology, the knowledge - and the electricity - to access the internet. Those who have the least income, the least resources, the least digital literacy and the least technology (including reliable electricity) will be shut out even further from the processes of making history. The 'accessibility' of the internet is a reality only for those who are already privileged. 
Such concerns have led us to reconsider online dissemination in two elements of our project - the database and interviews. We had initially expected that the database would be publically available to locate names of former Tranby students with their generalized origins (ie state and region, eg north west South Australia). Even though this would have made minimal information available, it now seems inappropriate. The project will therefore now offer the database only to the Tranby administration for purposes of developing an alumni list, as initially agreed. Further detailed consideration by the Board will be needed before the database, even in its minimal form, can be made accessible in a password-protected online context.

In the second redesign, we have decided that an online form of the project results is appropriate but that it will no longer focus on individual life stories. Instead, it will be in the form of a scrapbook - a collection of small and accessible items - a form adopted by most Tranby publications to date. This digital scrapbook would, like the exhibitions, display the activities at Tranby in which students were involved, rather than making interviewees' own life stories into the focus. This will allow substantial time for the interviewees to edit their transcripts and audio, to be stored as planned, as well as to identify how they would like to contribute to a discussion of the various activities to be included. But it will not make any former student vulnerable to present or future embarrassment or information misuse.

The visual metaphor for this project scrapbook will be an image designed by a student and adopted with permission as the Tranby logo over this period, although it is no longer in use for the whole organisation. 'The Meeting Tree' was a painting done in the early 1980s by Tranby student Billy Wilson from Bourke, which will offer the title for this project website, Around the Meeting Tree. The items on the site will include some students' names and their photographs, with their permission but will not follow the course of the oral history interviews or display any one student's 'life story' as may have been our initial expectation.

This online scrapbook will be composed of a number of elements, first with 'roots' of the Meeting Tree, which will provide brief introductions to the five key principles on which the Tranby cooperative had been built up from 1957 learning, land and heritage, cooperation and trade unions, justice and liberation. These principles have all flourished in the period we have researched, the early years of Indigenous control, from 1980 to 2000. So each 'root' would allow access to a number of the researched activities in which students were involved. The 'Learning' root, for example, would offer the user access to information about the courses and excursions at Tranby but also to the digitised Year Books, already published in hard copy but never before digitized, which refer to many of the events in which students took part. Similarly, the 'Cooperation and Trade Union' root would offer the records of the Tranby Co-op itself, in which students had a voice, as well as to the Trade Union Committee on Aboriginal Rights (TUCAR), in which students were involved as staff or as unionists.

Among the archival and memory items made accessible in this way would be some short, plain English and accessible essays of around 2000 words each, co- 
authored by various combinations of the research team with acknowledgement of the contributing interviewees. These essays would outline Tranby activities in the research period - drawing on student interviews with permission. These essays include, for example, one on the Heritage Sites course and another about the Aboriginal Development Unit, in which some former students were employed.

\section{Findings and Recommendations}

The Networking Tranby project always aimed to emphasise the students' experiences and particularly the person-to-person interactions and networks which Tranby had fostered. We expected that digital tools would play a significant role in all aspects of the project, from interviewing to online dissemination. However, findings from our research and from relevant literature have led us to reconsider some of our plans. We first list these findings and then suggest recommendations.

\section{Digital Methodology Findings:}

Interviews:

- Widespread social media use by Indigenous people - and particularly young people - is occurring in conditions of strong personal and community control. This reflects well-founded suspicion of research in colonial conditions. It is NOT an unqualified indication that social media will facilitate research unless it is under direct participant and collective community control.

- Individual focus was generally distrusted by Indigenous interview participants and by Indigenous staff, despite widespread interest in and enthusiasm for the research goals. The collective and collaborative processes of Indigenous oral cultures are one source of this unease.

- Recruiting interviewees: social media was less successful than expected. In addition, privacy requirements reduced interactivity. Most participants were contacted through word of mouth and 'snowball' networks of both Indigenous and non-Indigenous researchers.

- Recording: Consistent with above, while former students were often eager to participate in expanding and conserving the histories of adult education at Tranby and elsewhere, they were also often reluctant to be focused on as individuals through recording interviews. Participants were much happier to talk offrecording than to be recorded and to talk about activities in which they took part rather than their individual life stories.

\section{Database:}

- Information consistency: As with all small organisations, the data in archives was varied.

- Area of origin. Despite - or because - origin is such an important part of Indigenous social and personal identity, it was often only implicit on forms gathered by Tranby. It could at times only be 
learnt through word of mouth discussion between researchers and then by discrete inquiries by Indigenous researchers through their community links

\section{Web publication and digital dissemination}

- Widespread Indigenous use of internet platforms does not allay reluctance to participate in individually focused outcomes.

- Caution about loss of control over personal narratives with webbased presentation are widespread and legitimate in historical and contemporary terms.

- Eagerness for news and history. There was nevertheless significant eagerness to hear news of other students and about activities in the past at Tranby.

\section{Recommendations:}

1. Slow pace: We have slowed the pace of our oral history gathering - or had it slowed for us. The benefits of slow and responsive oral history gathering allow us to redesign our project in consultation with Indigenous interviewees and Tranby staff. This allows continuation of use of digital tools with high degrees of control by participants through reshaping of outcomes.

2. Control and community purpose: Indigenous participants' interest in control over digital tools should be recognized and supported. Tranby has responded by developing a program of digital student journals which will enable digital archiving but provide strong personal protections. Indigenous communities in North America have been involved in developing open source digital platforms like Mukurtu (http://mukurtu.org/) to enable conservation of narratives and histories yet ensure strong security protection. Staff in Jumbunna, the Indigenous Research and Learning Centre at UTS, are investigating the possible appropriate use of such platforms in Australian Indigenous research environments.

3. Consent: Continuing communication to ensure accessibility of consent modification is needed. There must therefore be content flexibility in any resultant website so that if consent needs to be altered or revised, material can be easily removed or protected.

4. Researchers: Maximise Indigenous roles and responsibilities - ie real power and, where appropriate, skill development - in interviewing, analysis and design of outcomes. This project has found considerable value in having a mix of Indigenous and non-Indigenous researchers, as it has to ensured the widest range of information came into the project. Nevertheless, but the role of Indigenous researchers has been critically important in all aspects of the project

5. Database: All database reports and visualisations (graphs, maps) should be carefully anonymised to ensure privacy. 
6. Online dissemination: should focus on activities and networks, rather than on individual life stories. In both online narratives of individuals and activities, continuous consent communication and related flexibility in web content design are essential.

\section{Reflection:}

Rather than tracing the individual life stories of former students, we will be focusing on the many and varied activities associated with Tranby - 'around the Meeting Tree' - in which students were involved. We will be drawing on our interviews, our archival searching and our database analysis and will as well be in conversation with interviewees. We hope in this way to avoid exposing any student to misuse of their story while eventually producing a valuable record of student involvement in a range of learning activities that are often overlooked in the more formal records of 'Aboriginal Education'.

${ }^{1}$ Gerald Friesen and Lucy Taksa: "Workers' Education In Australia and Canada: A Comparative Approach to Labour's Cultural History." Labour/Le Travail, Labour History 38, 71, 1996:170-197; Nikola Balnave and Greg Patmore: 'Aboriginal Co-operatives: The Role of Alf Clint', 7th Annual Conference of the Association of Academic Historians in Australian and New Zealand Business Schools, Auckland, New Zealand, 3rd November 2015; Kevin Cook and Heather Goodall: Making Change Happen: Black \& White activists talk to Kevin Cook about Aboriginal, Union \& Liberation politics. Aboriginal History \& ANU ePress, 2013.

${ }^{2}$ Andrew Dewdney with Sandra Phillips (ed) 1994: Racism, representation \& photography, Sydney: Inner City Education Centre; Durnan, Debbie and Boughton, 1999. Succeeding Against the Odds. The outcomes obtained by Indigenous students in Aboriginal community-controlled colleges. Adelaide: National Centre for Vocational Education Research.

${ }^{3}$ Emma S Rice, Emma Haynes, Paul Royce, and Sandra C Thompson: "Social Media and Digital Technology use among Indigenous young people in Australia: a literature review." International Journal for Equity in Health 15 (1) 2016 (online, 16 pages)

${ }^{4}$ Linda Tuhawai-Smith: Decolonising Methodologies: Research and Indigenous Peoples, London: Zed Books, 2012; Aileen Moreton-Robinson: 'Towards an Australian Indigenous women's standpoint theory: A methodological tool', Australian Feminist Studies, 28 (78) 2013, pp. 331-347; Martin Nakata: Disciplining the Savages: Savaging the Disciplines, Canberra: Aboriginal Studies Press, 2007; Lorina Barker: "'Hangin' out' and 'Yarnin': Reflecting on the experience of collecting oral histories." Oral History Association Australia, Sydney, 2006; Tracey Banivanua-Mar: Decolonisation and the Pacific: Indigenous Globalisation and the Ends of Empire. Cambridge, UK: Cambridge University Press, 2016.

${ }^{5}$ Alistair Thomson: 'Four Paradigm Transformations in Oral History', Oral History Review, 34(1), 2007 p70; Alexander Freund: “Confessing Animals”: Toward a Longue Durée History of the Oral History Interview' Oral History Review 41 (1), 2014, pp. 1-26.

${ }^{6}$ Barker, "'Hangin' Out'".

${ }^{7}$ Sione Latukefu: 'Oral traditions: An appraisal of their value in historical research in Tonga', The Journal of Pacific History, 3 (1), 1968, pp. 135-143; P.M. Mercer: 'Oral tradition in the Pacific: Problems of interpretation', The Journal of Pacific History, 14 (3), 1979, pp. 130-153; Donald Denoon and Roderic Lacey, editors: Oral tradition in Melanesia, Port Moresby: University of Papua New Guinea: Institute of Papua New Guinea Studies, 1981; Richard Feinberg: Polynesian Oral Traditions: Indigenous Texts and English Translations from Anuta, Solomon Islands, Kent State University Press, 2018 and Ruth Finnegan and Margaret Orbell (eds): South Pacific Oral Traditions, Bloomington: Indianna University Press, 1995; Ulrich Oslender: 'Revisiting the Hidden Transcript: Oral Tradition and Black Cultural Politics in the Colombian Pacific Coast Region', Environment and Planning D: Society and Space, vol. 25, 6, 2007: pp. 1103-1129 and Jan Vansina: Oral Tradition: A study in Historical Methodology. Translated by H.M. Wright. Chicago: Aldine Publishing Co., 1965 and Vansina: Oral Tradition as History. London: James Currey, 1985. 
${ }^{8}$ Sue Anderson, Jaimee Hamilton and Lorina L. Barker: 'Yarning up oral history: an Indigenous feminist analysis.' In Beyond Women's Words, edited by Katrina Srigley, Stacey Zembrzycki and Franca Iacovetta. London and New York: Routledge, 2018.

${ }^{9}$ Freund 'Confessing Animals'.

10 The interview in criminal proceedings discussed in Michel Foucault: Discipline and Punish: The Birth of the Prison, first published in France in 1975.

11 Philip Bonner: 'Apartheid, memory and other occluded pasts', in Culture, Memory, and Trauma, Oral History Association of South Africa, Proceedings, Third Annual National Oral History Conference, 2006, pp 11-33, http://uir.unisa.ac.za/bitstream/handle/10500/9787/ohasa 1 2006-22-052013.pdf?sequence=1\#page $=24$, accessed 31 May, 2018.

12 Thomson, 'Four Paradigm Transformations', p70.

${ }^{13}$ Anna Sheftel and Stacey Zembrzycki: 'Slowing Down to Listen in the Digital Age', Oral History Review, 77(1), 2017, pp. 94-112. They were discussing the commercialization arising from software companies, but this particular sentiment was expressed about the overall 'Linkage' partnership process by our potential interviewees, $\mathrm{p} 110$.

14 Tuhawai-Smith Decolonising Methodologies.; Barker '"Hangin' Out"', Moreton-Robinson, 'Indigenous Women's Standpoint Theory'; Nakata, Disciplining Savages.

${ }^{15}$ Bronwyn Carlson and Ryan Frazer: 'It's like going to a cemetery and lighting a candle: Aboriginal Australians, sorry business and social media', AlterNative: an international journal of indigenous peoples, 11(3), 2015, pp. 211-224.

16 Rice, et al: 'Social media and digital technology'.

${ }^{17}$ Sheftel and Zembrzycki, 'Slowing Down to Listen', p111.

${ }^{18}$ Sherna Berger-Gluck's best known work has involved her early practice, in, for example, her 1991 edited volume with Daphne Patai: Women's Words: The Feminist Practice of Oral History, New York, Routledge. More recently, in late 2017, Berger-Gluck spoke at the OHA conference, Long Beach, CA, and discussed the cautionary practices she has now developed. Some of these concerns are addressed in her 2011 paper: "Has Feminist Oral History Lost its Radical/ Subversive Edge?" in Oral History 39 (2): 63-72

${ }^{19}$ Sheftel and Zembrzycki, 'Slowing Down to Listen'

${ }^{20}$ Freund, paper delivered at 2017 OHA Conference, Long Beach, California. 